\title{
Measuring the Pro-Poorness of Income Growth within an Elasticity Framework
}

\author{
B. Essama-Nssah and Peter J. Lambert* \\ World Bank Poverty Reduction Group and University of Oregon
}

\begin{abstract}
Poverty reduction has become a fundamental objective of development, and therefore a metric for assessing the effectiveness of various interventions. Economic growth can be a powerful instrument of income poverty reduction. This creates a need for meaningful ways of assessing the poverty impact of growth. This paper follows the elasticity approach to propose a measure of pro-poorness defined as a weighted average of the deviation of a growth pattern from the benchmark case. The measure can help assess propoorness both in terms of aggregate poverty measures which are members of the additively separable class, and at percentiles. It also lends itself to a decomposition procedure, whereby the overall pattern of income growth can be unbundled, and the contributions of income components to overall pro-poorness identified. An application to data for Indonesia in the 1990s reveals that the amount of poverty reduction achieved over that period remains far below what would have been achieved under distributional neutrality. This conclusion is robust to the choice of a poverty measure among members of the additively separable class, and can be tracked back to changes in expenditure components.
\end{abstract}

Keywords: poverty, growth, pro-poorness, social evaluation

JEL classifications: I32, D63, R11

World Bank Policy Research Working Paper 4035, October 2006

The Policy Research Working Paper Series disseminates the findings of work in progress to encourage the exchange of ideas about development issues. An objective of the series is to get the findings out quickly, even if the presentations are less than fully polished. The papers carry the names of the authors and should be cited accordingly. The findings, interpretations, and conclusions expressed in this paper are entirely those of the authors. They do not necessarily represent the view of the World Bank, its Executive Directors, or the countries they represent. Policy Research Working Papers are available online at http://econ.worldbank.org.

"The authors are grateful to Martin Ravallion for encouragement and useful comments on an earlier version of this paper. 


\section{Introduction}

Effective development policy-making creates a need for ways of telling whether an intervention had (or is having) the intended effect. In the context of the definition of the Millennium Development Goals (MDGs), the international community has declared poverty reduction a fundamental objective of development, and therefore poverty reduction has become a metric for assessing effectiveness. This has led to an increased interest in poverty-focused policymaking and evaluation. Economic growth that accompanies the process of development is considered a powerful instrument of poverty reduction. It has been observed indeed that richer countries tend to have lower poverty incidence with respect to both income and non-income dimensions (World Bank 2001). Yet, countries with the same rates of economic growth do not necessarily have similar achievements in poverty reduction. When, then, do we declare a growth pattern propoor?

Generally speaking, pro-poor growth is economic growth that is "favorable" to the poor in some sense. The specific answer hinges on the interpretation of "favorable". This is essentially a value judgment issue. Over the past few years, several views have been expressed on this issue, as illustrated by a series of "One Pagers" published by the International Poverty Centre of the United Nations Development Programme (see Zepeda 2004, Kakwani 2004, Ravallion 2004 and Osmani 2005).

According to Kakwani and Pernia (2000), economic growth is pro-poor only when the incomes of the poor grow faster than those of the rich. This view focuses on distributional shifts associated with the growth process, and also underlies the indicator proposed by Son (2004). The second prevailing interpretation is that growth is pro-poor if it involves poverty reduction for some choice of a poverty index. Consistent with this second interpretation, Ravallion and Chen (2003) offer a measure of pro-poor growth based on the Watts (1968) index of poverty. Kraay (2004) has generalized this approach to other poverty measures. Because of its focus on relative gains, the first interpretation is referred to as a relative approach to assessing the pro-poorness of economic growth, while the second is considered an absolute approach because it is based on changes in both the rate of growth and the distribution of gains. 
Osmani (2005) argues that pinning the definition of pro-poor growth exclusively on distributional impact adds nothing to the traditional concern with equitable growth that can be traced back at least to Chenery et al. (1974). Consensus is now emerging around the absolute approach, due to the fact that pro-poorness is a characteristic of the whole growth process including both the growth rate and the distributional impact. This view underlies Ravallion's (2004) policy recommendation, that to make growth more povertyreducing involves a combination of policies to induce higher growth rates and to improve the distribution of gains. Furthermore, Osmani insists that poverty-reducing growth should not be declared as inevitably pro-poor in light of a general dissatisfaction with the scale of poverty reduction achieved by past growth experience in the developing world. He comes out in favor of a recalibrated absolute approach whereby economic growth is considered pro-poor if it achieves an absolute reduction in poverty greater than it would in a benchmark case. The choice of a benchmark is analogous to setting a level of significance in statistical analysis. Such a benchmark could be either a desirable growth pattern or a counterfactual ${ }^{1}$.

Ravallion and Chen (2003) and Kakwani et al. (2004) propose definitions and measurements of pro-poor growth that address the two issues raised by Osmani. These authors capture pro-poorness using the elasticity of a poverty index with respect to growth (i.e. changes in per capita income). Like many other indicators of pro-poor growth found in the recent literature, their measures involve a correction of the actual growth rate in a way that accounts for the distributional changes induced by the growth process. The distribution-correction factor is the ratio of the observed change in poverty to the change that would have occurred, had the growth process not caused any distributional shift. As noted earlier, Ravallion and Chen's "rate of pro-poor growth" is based on the Watts index of poverty. Kakwani et al.'s measure is known as the poverty equivalent growth rate (PEGR), and applies to members of the additive and separable class of poverty indices (including Watts). This is the growth rate that would induce the same amount of poverty reduction as the observed rate does, but under distribution neutrality. Each measure accounts for both the magnitude and the pattern of growth, and each uses distributional neutrality as a benchmark case. The measures can also be

\footnotetext{
${ }^{1}$ This is the pattern of growth that would have prevailed in the absence of the observed one.
} 
expressed as weighted averages of the growth rates of income among the poor. The weights are defined by the underlying poverty index. In particular, each measure can be represented as a distribution-correction factor times the observed growth rate.

Essama-Nssah (2005) offers a similar framework applying a broader social evaluation criterion to the growth rates of all incomes (not just for the poor). His specification of the social weights defining the evaluation criterion respects the DaltonPigou principle of transfers, and leads to a pro-poor growth indicator interpreted as the equally distributed equivalent growth rate. This is the growth rate that would be socially equivalent to the observed one, for some choice of the degree of aversion to inequality. This indicator too can be expressed in terms of the observed growth rate and a distribution-adjustment factor. The idea of a benchmark is embedded in the choice of the degree of aversion to inequality.

The purpose of this paper is to propose another elasticity-based method of measuring pro-poor growth. Instead of starting from the elasticity of a poverty index with respect to mean income (Kakwani et al. 2004, Kraay 2004, Ravallion and Chen 2003), the approach presented here relies on the description of a pattern of growth in terms of the elasticity of individual incomes with respect to the overall income. We use this method to assess pro-poorness both for a wide range of aggregate poverty indices, and also at percentiles in the income distribution. Moreover, we establish a general decomposition property, whereby the overall pattern of income growth can be unbundled, and the contributions of income components to overall pro-poorness can be identified, in terms of any particular poverty index and at any percentile in the distribution. Our framework of analysis is fully consistent with Osmani's (2005) conceptual framework, and permits us to bring out clear connections with some existing pro-poorness indicators. In casting these in the same mold as our new measures, we hope to also bring some clarity and unity to the emerging and as yet quite disparate pro-poorness literature.

The outline of the paper is as follows. Section 2 characterizes a pattern of income growth based on the responsiveness of individual incomes to changes in total income. Section 3 defines our measure of pro-poor growth using either an aggregate poverty index or a poverty curve and distribution neutrality to define a benchmark. The decomposability of our measure is fully explored in this section also. Empirical 
illustrations are briefly considered in section 4, based on data from Indonesia for 19932002. Concluding remarks are made in section 5. In particular, it is found that the overall poverty reduction observed in Indonesia for the period under consideration was not pro-poor because a distributionally neutral growth pattern would have done more.

\section{Feasible Growth Patterns}

Given our choice of benchmark, we need a calculus within which the effects of distributional shifts induced by the growth process can be readily quantified and analyzed. We rely on a little-noticed approach developed in Lambert (1984) to define and characterize a "growth pattern" in terms of its feasibility and pro-poorness.

Let an individual's income be $x$ and let $y$ stand for total income in a population of size $N$. If $f(x)$ represents the frequency density function for income, then total income is defined by the following expression.

$$
y=N \int_{0}^{m_{x}} x f(x) d x
$$

where $m_{x}$ is the maximum income. Denote by $q(x)$ the point elasticity of $x$ with respect to $y$. The function $q(x)$ is a measure of the responsiveness of individual incomes to changes in the overall income. In other terms, if total income $y$ grows by $1 \%, x$ grows by $q(x)$ percent. This elasticity is defined formally as follows

$$
q(x)=\frac{y}{x} \cdot \frac{d x}{d y}=\frac{d \ln (x)}{d \ln (y)}
$$

The function $q(x)$ defines a growth pattern and is the anchor of our measure of propoorness. $^{2}$ Ravallion and Chen (2003) define their growth incidence curve (or GIC) as the growth rate of income at the $p^{\text {th }}$ percentile point of the income distribution. Thus, expression (2.2) indicates that our growth pattern is essentially a normalized GIC. ${ }^{3}$

The function $q(x)$ must obey a feasibility constraint in order to be considered a legitimate representation of a growth pattern. Suppose the overall income increases by

${ }^{2}$ Note that population growth per se does not influence $q(x)$, which could alternatively be defined as the elasticity of $\mathbf{x}$ with respect to the mean income $y / N$.

${ }^{3}$ Ravallion and Chen's growth incidence curve takes the form $g_{R C}(p)=\frac{d x}{x}$ when $p=\int_{0}^{x} f(t) d t$. In other words, from (2.2), $g_{R C}(p)=q(x) \frac{d y}{y}$. 
$1 \%$, then $q(x)$ is feasible if all of the implied individual income growths add up correctly to this $1 \%$. Formally, as shown in Lambert (1984), $q(x)$ must satisfy the following restriction in order to be a potentially observable growth pattern.

$$
\int_{0}^{m_{x}} x[q(x)-1] f(x) d x=0
$$

The demonstration of this feasibility condition, along with the proofs of all subsequent theorems, can be found in the Appendix.

\section{The Pro-Poorness of a Growth Pattern}

\section{Underlying Value Judgments}

When is a feasible growth pattern pro-poor? Fundamentally, assessing propoorness of growth is an exercise in social evaluation that requires a criterion for comparing alternative social states, each characterized by a growth pattern. The answer to this question thus hinges on the choice of a social evaluation criterion, and the determination of a benchmark growth pattern against which to judge the observed one ${ }^{4}$.

With respect to the choice of a social evaluation criterion, we focus here on members of a class of additively separable poverty measures. Kakwani (1999) defines such a class starting from the notion of deprivation. Now let $x$ represent the level of welfare enjoyed by an individual in the society, and let $z$ be the poverty line. Let $\psi(x \mid z)$ stand for an indicator of deprivation at the individual level. The following restrictions are imposed on this indicator: (i) it is equal to zero when the welfare level of the individual is greater than or equal to the poverty line; (ii) the indicator is a decreasing convex function of welfare, given the poverty line.

Poverty measures of the Kakwani class capture the average deprivation suffered by the whole society. A measure in this class may be written, as:

$$
P=\int_{0}^{z} \psi(x \mid z) f(x) d x
$$

where $\psi(x \mid z)$ is some particular indicator of deprivation. ${ }^{5}$

\footnotetext{
${ }^{4}$ This is a translation of the fundamental idea of causal inference according to which the effect of one cause can be understood only in relation to another cause (Holland 1986).

${ }^{5}$ See also Atkinson (1987) and Foster and Shorrocks (1991) for this general form.
} 
The class of such poverty measures is called additively separable because the deprivation felt by an individual depends only on a fixed poverty line and her/his level of welfare and not on the welfare of other individuals in society. When the population is divided exhaustively into mutually exclusive socioeconomic groups, this class of measures allows one to compute the overall poverty as a weighted average of the poverty in each group. The weights here are equal to population shares. Thus such indices are also additively decomposable.

The choice of a benchmark growth path implies the identification of a feasible growth pattern that is considered not pro-poor. We use a growth pattern that is distributionally neutral (all incomes growing at the same rate) as our benchmark. Thus, $a$ feasible growth pattern would be declared pro-poor if it reduces poverty more than equiproportionate growth would, for some choice of a poverty index. Osmani (2005) argues that the choice of a benchmark might not be so critical in determining whether a particular set of policies is more likely to be more pro-poor than another as this involves only a comparison of the poverty-reducing effect of the alternative policies. People could agree with the conclusions from such a comparison and yet disagree on the precise choice of the benchmark.

\section{Pro-Poorness for a Given Poverty Index}

For the poverty measure defined by (3.1), the growth elasticity of $P$ for the growth pattern $q(x)$ may written as follows

$$
\phi_{P}(q)=\frac{y}{P} \cdot \frac{d P}{d y}=\frac{d \ln (P)}{d \ln (y)}=\frac{1}{\gamma} d \ln (P)
$$

where $\gamma=\frac{d y}{y}$. The following theorem shows how to express this elasticity as a function of the growth pattern.

\section{Theorem 1:}

For the poverty index $P$ defined in (3.1), $\phi_{P}(q)=\int_{0}^{z} \frac{x \psi^{\prime}(x \mid z) q(x) f(x) d x}{P}$ 
Note from the definition of the slope of the Lorenz curve $L(p)$ at a given percentile $p=\int_{0}^{x} f(t) d t$, that $q(x)=q_{0}+\frac{d \ln \left[L^{\prime}(p)\right]}{\gamma}$. In other words, the actual growth pattern defining $\phi_{P}(q)$ is equal to the pattern associated with distributional neutrality plus an adjustment factor indicating the extent to which changes in inequality cause the actual pattern to deviate from the benchmark $\left(\mathrm{q}_{0}=1\right)^{6}$

Typically, $\phi_{P}(q)$ will be negative since positive growth induces poverty reduction for $x<z$. The reduction in poverty associated with a $1 \%$ increase in total income $\mathbf{y}$ according to the growth pattern $q(x)$ is equal to $-P \phi_{P}(q)$. Had this growth been distributionally neutral (the benchmark case), the reduction in poverty would be $-P \phi_{P}\left(q_{0}\right)$, where $q_{0}(x)=1$ for all $x$. Thus we propose to measure the pro-poorness of the growth pattern $q(x)$ by the extent to which the former exceeds the latter. Formally, we define our measure of pro-poorness for a poverty index $P$ satisfying (3.1) as

$$
\pi_{P}(q)=P\left[\phi_{P}\left(q_{0}\right)-\phi_{P}(q)\right]
$$

The term within brackets is equal to the growth elasticity of poverty in the benchmark case (a negative number) plus the absolute value of the observed growth elasticity of poverty (a positive number). Thus, if $\pi_{P}(q)>0$, the positive number dominates the negative one. This means poverty falls more, according to index $P$, when growth is $q(x)$ than if it were distributionally neutral. If $\pi_{P}(q)<0$, the reverse holds: actual growth does not lead to significant poverty reduction.

The following theorem shows clearly the extent to which the characteristics of the growth pattern $q(x)$ and the choice of the deprivation function $\psi(x \mid z)$ determine our measure of pro-poorness. Simply put, pro-poorness is a weighted sum of the deviations of a growth pattern from the benchmark case, up to the poverty line.

\footnotetext{
6 Indeed, the growth elasticity of $\mathrm{P}$ can be decomposed additively into scale and distributional components: from theorem $1, \phi_{P}(q)=\phi_{\mu P}+\phi_{\lambda P}$, where $\phi_{\mu P}=\frac{1}{P} \int_{0}^{z} x \psi^{\prime}(x \mid z) f(x) d x=\phi_{P}\left(q_{0}\right)$ and $\phi_{\lambda P}=\frac{1}{P} \int_{0}^{z} x \psi^{\prime}(x \mid z)[q(x)-1] f(x) d x$. Our measure of pro-poorness to be presented in Theorem 2 will in fact be a simple transformation of the latter term $\phi_{\lambda P}$ (see on).
} 


\section{Theorem 2:}

The measure of pro-poorness of a growth pattern $q(x)$ for the poverty index $P$ defined in (3.1) is equal to

$$
\pi_{P}(q)=\int_{0}^{z}\left\{-x \psi^{\prime}(x \mid z)\right\}[q(x)-1] f(x) d x
$$

It is clear that if $q(x)>1 \forall x<z$, then $\pi_{P}(q)>0 \forall P$ satisfying (3.1). ${ }^{7}$ Note however that it is not necessary that $q(x)>1 \forall x<z$ for a growth pattern to be judged pro-poor in terms of a specific poverty index. ${ }^{8}$

${ }^{7}$ We may also view this sufficiency condition in terms of Ravallion and Chen's growth incidence curve.
From the definition in footnote $2, \pi_{P}(q)=\frac{1}{\gamma} \int_{0}^{z}\left\{-x \psi^{\prime}(x \mid z)\right\}\left[g_{R C}(p)-\gamma\right] f(x) d x$ where $\gamma=\frac{d y}{y}$ as in (3.2). Thus pro-poorness obtains for the poverty indices considered here, if income at every percentile up to the poverty line grows faster than aggregate income. For another perspective, notice that, by Theorem 2, $\pi_{P}(q)=-\mathrm{P} . \phi_{\lambda P}$ where $\phi_{\lambda P}$ is the distributional component of $\phi_{P}(q)$ defined in footnote 5. Thus, if $\phi_{\lambda P}$ is negative the associated growth pattern will be pro-poor - and for this to happen, it is clearly enough to have income grow faster than average for all percentiles up to the poverty line.

${ }^{8}$ Theorem 2 can be used to compute pro-poorness for many familiar poverty indices. Let $W$ be the Watts index, $D$ the normalized poverty deficit and $F G T_{\alpha}$ the Foster, Greer and Thorbecke (1984) poverty index with $\alpha \geq 1$. The deprivation functions for these measures are $\psi_{W}(x \mid z)=\ln \left(\frac{z}{x}\right), \psi_{D}(x \mid z)=1-\frac{x}{z}$ and $\psi_{a}(x \mid z)=\left(1-\frac{x}{z}\right)^{\alpha}$ for $\mathrm{x}<\mathrm{z}$, and zero otherwise. The pro-poorness measures for $W, D$ and $F G T_{2}$ (the socalled squared poverty gap) are $\pi_{W}(q)=\int_{0}^{z}[q(x)-1] f(x) d x, \quad \pi_{D}(q)=\int_{0}^{z} \frac{x}{z}[q(x)-1] f(x) d x$ and $\pi_{F G T_{2}}(q)=2 \int_{0}^{z} \frac{x}{z}\left(1-\frac{x}{z}\right)[q(x)-1] f(x) d x$. Clearly, for none of these is $\{q(x)>1 \forall x<z\}$ a necessary condition for a growth pattern $q(x)$ to be judged pro-poor. Notice that the Watts index is more pro-poor than the normalized poverty deficit for all feasible growth patterns $q(x)$, pro-poor or not. Also, when a growth pattern is pro-poor according to the Watts index, so that $\pi_{W}(q)>0$, we must have $\int_{0}^{z} q(x) f(x) d x>H$, whence $\frac{1}{H} \int_{0}^{H} g_{R C}(p) d p>\frac{d y}{y}$ (see footnote 2). Hence, if the area beneath Ravallion and Chen's GIC up to the headcount ratio, normalized by the headcount ratio itself, exceeds [is less than] the actual growth rate, then the growth pattern is [is not] pro-poor for the Watts index. Ravallion and Chen (2003) note this result and characterize $\frac{1}{H} \int_{0}^{H} g_{R C}(p) d p$ as "the mean growth rate for the poor" (ibid., page 96). 
In order to explore decomposability of the growth elasticity of poverty $\phi_{P}(q)$ and pro-poorness index $\pi_{P}(q)$ across income components, we first suppose, for simplicity, that each person's income $x$ has two components, $x=x_{1}+x_{2}$. The overall growth pattern is then an income-share-weighted average of the component growth patterns:

$$
\begin{gathered}
q(x)=\frac{y}{x} \cdot \frac{d x}{d y}=\frac{y}{x_{1}+x_{2}} \cdot \frac{d x_{1}+d x_{2}}{d y}=\alpha(x) \cdot \frac{y}{x_{1}} \cdot \frac{d x_{1}}{d y}+(1-\alpha(x)) \cdot \frac{y}{x_{2}} \cdot \frac{d x_{2}}{d y} \\
=\alpha(x) \cdot q\left(x_{1}\right)+(1-\alpha(x)) \cdot q\left(x_{2}\right)
\end{gathered}
$$

where $\alpha(x)=\frac{x_{1}}{x}$. Multiplying through by $x$, we get

$$
x q(x)=x_{1} \cdot q\left(x_{1}\right)+x_{2} \cdot q\left(x_{2}\right)
$$

and, just as easily,

$$
x[q(x)-1]=x_{1} \cdot\left[q\left(x_{1}\right)-1\right]+x_{2} \cdot\left[q\left(x_{2}\right)-1\right]
$$

By substituting from these expressions into the integrals defining $\phi_{P}(q)$ and $\pi_{P}(q)$ in Theorems 1 and 2 respectively, we arrive at the following result.

\section{Theorem 3:}

If income $x$ has two components, $x=x_{1}+x_{2}$, the growth elasticity and propoorness measures $\phi_{P}(q)$ and $\pi_{P}(q)$ for the poverty index $\mathrm{P}$ defined in (3.1) can be decomposed, as $\phi_{P}(q)=\phi_{1 P}(q)+\phi_{2 P}(q)$ and $\pi_{P}(q)=\pi_{1 P}(q)+\pi_{2 P}(q)$ respectively, where $\phi_{i P}(q)=\int_{0}^{z} \frac{x_{i} \psi^{\prime}(x \mid z) q\left(x_{i}\right) f(x) d x}{P}$ and $\pi_{i P}(q)=\int_{0}^{z}\left\{-x_{i} \psi^{\prime}(x \mid z)\right\}\left[q\left(x_{i}\right)-1\right] f(x) d x, i$ $=1,2$. In the case of $n>2$ income components, we have $\phi_{P}(q)=\sum_{i=1}^{n} \phi_{i P}(q)$ and $\pi_{P}(q)=\sum_{i=1}^{n} \pi_{i P}(q), i=1,2, \ldots \mathrm{n} .{ }^{9}$

9 These follow because $x q(x)=\sum_{i=1}^{n} x_{i} q\left(x_{i}\right)$ and $x[q(x)-1]=\sum_{i=1}^{n} x_{i}\left[q\left(x_{i}\right)-1\right]$ when $x=\sum_{i=1}^{n} x_{i}$. 
Using these decompositions, we may "unbundle" a pattern of income growth and thereby identify the contributions of income components to overall pro-poorness. ${ }^{10}$

\section{Relationship with Kakwani et al's (2004) measures of pro-poorness.}

It is illuminating to expose the relationship between our measure of pro-poorness and those advocated by Kakwani et al. (2004), whose analytical framework is similar to ours in some respects. Indeed, these authors measure poverty with members of the class of additively separable indices. They also use distributional neutrality as a benchmark. They develop a measure known as the poverty equivalent growth rate (PEGR). It is the uniform growth rate, $\gamma_{e}$, that will induce the same level of poverty reduction as the actual growth rate $\gamma$ in our case, but under distribution neutrality. Within our framework, the $P E G R$ is the solution to the following equation.

$$
\phi_{P}(q) \cdot \gamma=\phi_{P}\left(q_{0}\right) \cdot \gamma_{e}
$$

Defining

$$
K_{P}(q)=\frac{\phi_{P}(q)}{\phi_{P}\left(q_{0}\right)}
$$

the $P E G R$ can be written as:

$$
\gamma_{e}=K_{P}(q) \cdot \gamma
$$

In this form, $\gamma_{e}$ expresses the $P E G R$ as the product of a distribution-correction factor $\left(K_{P}(q)\right)$ and the actual growth rate $(\gamma)$. To understand the behavior of this correction factor, note that its sign depends on the comparison of the benchmark elasticity with the actual one:

$$
\begin{aligned}
K_{P}(q) & > \\
& <0 \Leftrightarrow \phi_{P}\left(q_{0}\right) \\
& > \\
& <
\end{aligned}
$$

In particular, if both elasticities have the same sign (i.e. negative) and the benchmark elasticity is greater than the actual elasticity, the correction factor will be greater than

10 Examples of (gross) income components include employment and self-employment income, investment income, pensions, family support and unemployment benefits. Income taxes would be a negative component. The decompositions can also be used for expenditure-based poverty analysis. In Son (2006), pro-poorness of income and expenditure components in Thailand are investigated, albeit without allowing for growth patterns which are non-equiproportionate. 
one. Still assuming the same sign, if the benchmark elasticity is less than the actual one, then the adjustment factor is positive but less than one. Finally, if these elasticities are of opposite signs, then the correction factor is negative. What emerges from these considerations is that the correction factor adjusts the actual growth rate up or down according to whether the distributional changes induced by the growth process favor the poor or not.

Theorem 1 allows us to rewrite the correction factor of Kakwani et al as follows:

$$
K_{P}(q)=\frac{\int_{0}^{z} x \psi^{\prime}(x \mid z) q(x) f(x) d x}{\int_{0}^{z} x \psi^{\prime}(x \mid z) f(x) d x}
$$

This is a weighted average of the individual growth elasticities along the growth path up to the poverty line. The weights are defined by the underlying poverty index, through the specification of the deprivation function $\psi(x \mid z)$.

Multiplying in (3.11) by the observed growth rate of total income, $\gamma$, we note that (as in Kakwani et al. 2004) the PEGR can be expressed as a weighted average of the growth rates of incomes, $g(x)=\gamma q(x)$, along the growth path up to the poverty line :

$$
\gamma_{e}=\frac{\int_{0}^{z} x \psi^{\prime}(x \mid z) g(x) f(x) d x}{\int_{0}^{z} x \psi^{\prime}(x \mid z) f(x) d x}
$$

Some parallels between our measure and those of Kakwani et al are now evident.

First, in both approaches, the growth elasticity of a poverty index for a given growth pattern $q(x)$ is compared with the value that would occur in the benchmark scenario of distributionally neutral growth (when $q_{0}(x)=1$ for all $x$ ). We make an additive comparison (as in (3.3), $\pi_{P}(q)=P\left[\phi_{P}\left(q_{0}\right)-\phi_{P}(q)\right]$ ), whilst Kakwani et al's correction factor does it in ratio form $\left(K_{P}(q)=\frac{\phi_{P}(q)}{\phi_{P}\left(q_{0}\right)}\right.$ recall (3.8)). The respective estimates thus use different calibrations, but are both in line with Osmani's proposal to compare the actual growth experience with what would occur in the benchmark case. Some hypothetical numerical examples illustrate the difference between the two approaches, and will perhaps also aid the reader's understanding of our results for the Indonesian growth experience which are to follow. Suppose first that $\phi_{P}(q)=-0.5$ and 
$\phi_{P}\left(q_{0}\right)=-0.3$, i.e. that for every $1 \%$ increase in total income, poverty is reduced $0.2 \%$ more by the growth pattern $q(x)$ than by distributionally-neutral growth. Our measure $\pi_{P}(q)$ records the $0.2 \%$ benefit to poverty, as $\pi_{P}(q)=0.002 P$, whilst Kakwani et al's $K_{P}(q)$ records that poverty falls 1.67 times faster than under equiproportionate growth: $K_{P}(q)=\frac{5}{3}$. Second, suppose that $\phi_{P}(q)=-0.1$, with $\phi_{P}\left(q_{0}\right)=-0.3$ as before. This growth pattern reduces poverty, but by $0.2 \%$ less than distributionally-neutral growth: $\pi_{P}(q)=-$ $0.002 P$. In this case, $K_{P}(q)=\frac{1}{3}:$ the benefit to poverty is only one-third that of a smooth growth rate experienced by all income units. Finally, suppose that again $\phi_{P}\left(q_{0}\right)=-0.3$ but this time $\phi_{P}(q)=+0.5$, say, so that despite the $0.3 \%$ poverty-reducing effect of distributionally-neutral growth, actual poverty increases by $0.5 \%$. Our $\pi_{P}(q)$ records propoorness as negative, $-0.8 \%$ of $P$, i.e. growth is anti-poor; and $K_{P}(q)=-\frac{5}{3}$.

There is a second respect in which our and the Kakwani et al approaches may be compared and contrasted. Each pro-poorness index can be portrayed as an aggregate of income change characteristics along the growth path, up to the poverty line. Whilst our $\pi_{P}(q)$ is given as a weighted sum of deviations of individual elasticities from the common benchmark value (theorem 2), Kakwani et al's correction factor is a weighted average of individual elasticities (see (3.11)), whilst their PEGR is a weighted average of growth rates $($ see $(3.12)) .^{11}$

\footnotetext{
11 The reader may verify that the Kakwani et al correction factors $\mathrm{K}_{\mathrm{P}}(\mathrm{q})$ for $W, D$ and $F G T_{2}$ are: $\frac{1}{H} \int_{0}^{z} q(x) f(x) d x=\frac{1}{H \gamma} \int_{0}^{H} g{ }_{R C}(p) d p, \frac{1}{H-D} \int_{0}^{z} \frac{x}{z} q(x) f(x) d x$ and $\frac{1}{D-F G T_{2}} \int_{0}^{z} \frac{x}{z}\left(1-\frac{x}{z}\right) q(x) f(x) d x$ respectively. The first of these equals Ravallion and Chen's (2003) "mean growth rate for the poor" (see footnote 7). The relationship between the pro-poorness of the Watts index and normalized poverty deficit, noted for our measure in footnote 7, is not apparent in the Kakwani et al framework.
} 
Finally, our measures yield the convenient decomposition formulae $\phi_{P}(q)=\sum_{i=1}^{n} \phi_{i P}(q)$ and $\pi_{P}(q)=\sum_{i=1}^{n} \pi_{i P}(q)$ as in Theorem 3, whilst the Kakwani et al constructions have not been shown by their authors to have such properties. ${ }^{12}$

\section{Pro-Poorness at Percentiles}

The focus so far has been on the formulation of an overall judgment about the pro-poorness of a growth pattern. We now consider a way of assessing pro-poorness at certain segments of the distribution of the benefits from growth. Kakwani et al do not propose a way to measure pro-poorness at percentiles in the income distribution. We can do it here: our additive framework lends itself readily to such an exercise.

We base this assessment on a poverty curve akin to the so-called three I's of poverty (TIP) curve of Jenkins and Lambert (1997) or the absolute poverty gap profile (APGP) curve of Shorrocks (1998). The curve is obtained by partially cumulating individual contributions to the overall poverty from the biggest one downwards (i.e. from the poorest individual to the richest). Individual contributions are computed on the basis of the deprivation function $\psi(x \mid z)$ which defines the poverty index $P$.

Formally, let $F(x)$ be the distribution function for income and let $p=F(t) \in[0,1]$. We may define a generalized $T I P$ curve $J_{P}($.) for the poverty index $P$ by

$$
J_{P}(p)=\int_{0}^{t} \psi(x \mid z) f(x) d x \quad, 0 \leq p \leq 1
$$

Clearly, this poverty curve is upward sloping and concave. Also, we note that $J_{P}(p)=P \forall p \geq H=F(z)$ where $H$ is the headcount ratio. For the normalized poverty gap $D$, the curve $J_{D}(p)$ is precisely the normalized TIP or APGP curve of Jenkins and Lambert (1997) and Shorrocks (1998). ${ }^{13}$

12 In fact, Kakwani et al's correction factor can be expressed as a weighted average of component measures. Substituting from (3.5) into (3.11), we see that $K_{P}(q)=\sum_{i=1}^{n} \beta_{i} K_{i P}(q)$ where $\beta_{i}=\frac{\int_{0}^{z} x_{i} \psi^{\prime}(x \mid z) f(x) d x}{\int_{0}^{z} x \psi^{\prime}(x \mid z) f(x) d x}$. Similarly, $\gamma_{e}=\sum_{i=1}^{n} \beta_{i} \gamma_{i e}$.

${ }^{13}$ The reader may use (3.13), along with the specifications of the deprivation functions for the Watts, normalized poverty gap and squared poverty gap indices given in footnote 7 , to obtain analytical expressions for the curves $J_{W}(p), J_{D}(p)$ and $J_{F G T_{2}}(p)$. 
Figure 3.1 presents a picture of poverty in Indonesia in 1993 based on data that we describe below in the empirical section, using the normalized TIP curve. This curve shows a graphical summary of incidence, intensity and inequality dimensions of aggregate poverty based on the distribution of normalized poverty gaps. Indeed, the length of the non-horizontal segment of the curve reveals incidence. The height of the curve represents intensity, while the degree of concavity translates inequality among the poor.

The following theorem identifies the form of the measure of pro-poorness at percentile $p$, when this is expressed as the effect of a growth pattern $q(x)$ on $J_{P}(p)$ over and above the effect that would obtain under distribution neutrality. ${ }^{14}$ This measure also decomposes across income components:

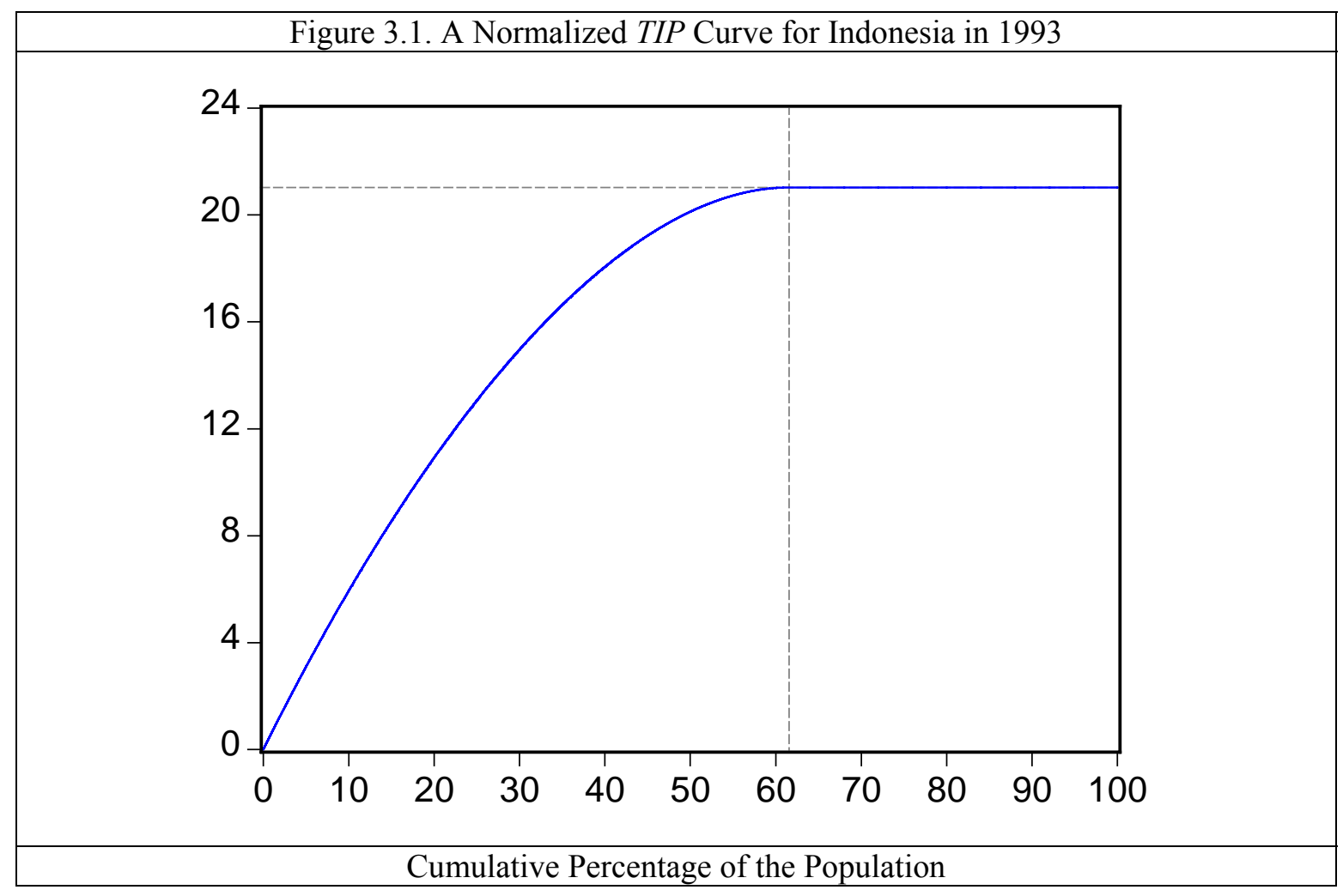

14 If $\zeta_{P}(q \mid p)$ is the growth elasticity of $J_{P}(p)$ for the growth pattern $q(x)$, then $\pi_{J}(q \mid p)$ is defined by the equation $\pi_{J}(q \mid p)=J_{P}(p)$. $\left[\zeta_{P}\left(q_{o} \mid p\right)-\zeta_{P}(q \mid p)\right]$, in the same way that $(3.3)$ defines $\pi_{P}(q)$. 


\section{Theorem 4:}

If $p=F(t) \in[0,1]$, then $\pi_{J}(q \mid p)=\int_{0}^{t}\left\{-x \psi^{\prime}(x \mid z)\right\}[q(x)-1] f(x) d x$. In the case of $n \geq 2$ income components, $x=\sum_{i=1}^{n} x_{i}$, we have $\pi_{J}(q \mid p)=\sum_{i=1}^{n} \pi_{i J}(q \mid p)$ where $\pi_{i J}(q \mid p)=\int_{0}^{t}\left\{-x_{i} \psi^{\prime}(x \mid z)\right\}\left[q\left(x_{i}\right)-1\right] f(x) d x$.

The pro-poorness measure at a fixed percentile $p$ is entirely analogous to the one found in theorem 2. In fact, when $p \geq H$, equivalently $t \geq z$, theorem 4 leads to a formula for the indicator of pro-poorness that is identical to the one obtained in theorem 2. The condition for a growth pattern $q(x)$ to be pro-poor at every percentile $p \leq H$ for the poverty index $P$ is the following.

$$
\int_{0}^{t}\left\{-x \psi^{\prime}(x \mid z)\right\}[q(x)-1] f(x) d x>0 \forall t \leq z
$$

Clearly, this condition is stronger than merely requiring that $q(x)$ be pro-poor for the overall poverty measure $P$.

The condition $q(x)>1 \forall x<z$ is of course sufficient for growth to be judged propoor at every percentile $p$ for all the poverty indices $P$ in the class we are considering. Suppose that growth is judged pro-poor for a certain index $P$ at the lowest percentiles. The following theorem shows that this growth must be experienced more-thanproportionately by the poorest individuals.

\section{Theorem 5:}

If there is a cut-off percentile $p_{0}>0$ such that growth is pro-poor $\left(\pi_{J}(q \mid p)>0\right)$ for all percentiles below and up to $\mathrm{p}_{0}$, then there must be an income level $\mathrm{v}$, below the poverty line, such that the elasticity of all individual incomes $x<v$ with respect to the overall mean is greater than one. Formally, we state that:

$$
\exists p_{0}>0: \pi_{J}(q \mid p)>0 \forall p \leq p_{0} \Leftrightarrow \exists v<z: q(x)>1 \forall x \in[0, v] .
$$

Notice that this result goes both ways. Pro-poorness for the very poorest for one index $P$ is only securable if income growth at the very bottom is more than proportionate 
to overall growth - and then pro-poorness at the very bottom follows for every index $P$ in our class. This Rawlsian-type condition is intuitively reasonable.

The local pro-poorness measures $\pi_{J}(q \mid p)$ for any particular poverty index $P$ satisfying (3.1) tell us how a growth pattern affects the aggregated deprivations of the $100 \mathrm{p} \%$ poorest in the income distribution, $0 \leq p \leq 1$, relative to equiproportionate income growth. The measurement takes place at percentiles along the generalized TIP curve $J_{P}(p)$, defined in (3.13). When $p$ reaches the headcount percentile, the local pro-poorness measure becomes equal to the global one: $p \exists F(z)=H \Rightarrow J_{P}(p)=P \& \pi_{J}(q \mid p)=\pi_{P}(q)$. What does the local pro-poorness measure tell us, for $p<H$, that the global one cannot?

We examine this question now for a particular poverty index, namely for the normalized poverty deficit, $P=D$. In this case, the generalized $T I P$ curve is the actual TIP curve. For clarity, we denote the local pro-poorness measure $\pi_{T I P}(q \mid p)$ in this special case. Thus

$$
z \cdot \pi_{D}(q)=\int_{0}^{z} x[q(x)-1] f(x) d x
$$

(as in footnote 7 ), and for $\mathrm{p}=\mathrm{F}(\mathrm{t})$ where $\mathrm{t} \leq \mathrm{z}$, we have

$$
z \cdot \pi_{T I P}(q \mid p)=\int_{0}^{t} x[q(x)-1] f(x) d x
$$

Although $\pi_{D}(q)$ depends only on the growth pattern $q(x)$ for $x<z$, and compresses all of that information into a single number, in fact, $\pi_{D}(q)$ reveals quite a lot about income growth among the non-poor, as Theorem 6 shows.

\section{Theorem 6:}

Suppose that $\pi_{D}(q)$ is explained as in (3.15) by a growth pattern $q(x)$. Then $\pi_{D}(q)$ is also explained by a modified growth pattern $q^{*}(x)$ such that for $x<z, q^{*}(x)=$ $q(x)$ and for $x>z, q^{*}(x)$ is constant, with value $q^{*}=1-\frac{z}{\mu} \cdot \frac{\pi_{D}(q)}{\theta}$, where $\mu$ is mean income and $\theta$ is the fraction of all income held by the non-poor. 
The number $q^{*}$ could be defined as the "pro-poorness equivalent uniform growth rate among the non-poor". ${ }^{15}$ Clearly,

$$
\begin{aligned}
& \begin{array}{rlrl} 
& > & & < \\
q^{*} & =1 \Leftrightarrow \pi_{D}(q) & =0
\end{array} \\
& <\quad>
\end{aligned}
$$

If growth is overall pro-poor/neutral/pro-rich for $D$, then the equivalent smooth growth for the non-poor must be less than proportionate/proportionate/more than proportionate and vice versa. A corollary is that pro-poorness for the normalized poverty deficit $D$ rules out growth patterns with $q(x)>1 \forall x>z$; and growth patterns for which $q(x)<1 \forall x>z$ are necessarily pro-poor for $D$.

For a growth pattern $q(x)$ which is continuous in $x$, constant for $x>z$ and such that $[q(x)-1]$ changes sign once or twice on $[0, z]$, being first positive (so that that the growth pattern is pro-poor at the poorest percentiles whatever the poverty measure used in the evaluation, by Theorem 5), it is easy to see that overall pro-poorness (or overall neutrality) for the normalized poverty deficit occurs if there is a single sign change and overall pro-richness (or overall neutrality) occurs if there are two sign changes. ${ }^{16}$ In general, we can expect to see overall pro-poorness associated with pro-richness at some percentiles among the poor (and conversely). The percentile pro-poorness measure $\pi_{T I P}(q \mid p)$ can reveal facets of a growth pattern that the overall measure $\pi_{D}(q)$ certainly cannot.

\footnotetext{
15 Thus q* enjoys a similar relationship with $\pi_{D}(q)$ as Ravallion and Chen's (2003) "mean growth rate for the poor" does with $\pi_{W}(q)$, the pro-poorness measure for the Watts index (recall footnote 7).

${ }^{16}$ This is because the constant value of $q(x)$ for $x>z$ is $q^{*}=1-\frac{z}{\mu} \cdot \frac{\pi_{D}(q)}{\theta}$ from Theorem 6 , and $q(z)=$ $q^{*}$ can be inferred from continuity. Hence, for such a growth pattern, pro-poorness can be read simply from the value $q(z): \pi_{D}(q)=[1-q(z)] \cdot \frac{\mu \theta}{z}$. Shortly, we shall encounter a growth pattern for Indonesia for which $[q(x)-1]$ changes sign twice on $[0, z]$, being first negative, and with five sign changes overall. Note that in all scenarios, $[q(x)-1]$ must change sign at least once, because of (2.3).
} 


\section{Empirical Considerations}

To illustrate how the above framework might help an analyst assess the propoorness of economic growth in a particular country, we use data for Indonesia presented in table 4.1 for the period 1993-2002.

Table 4.1. Distribution of Household Expenditure in Indonesia (1993-2002)

\begin{tabular}{llllllllllll}
\hline Year & Mean & $\begin{array}{l}\text { Lowest } \\
\text { Decile }\end{array}$ & 2nd & 3rd & $4^{\text {th }}$ & 5th & 6th & 7h & 8th & 9th & $10^{\text {th }}$ \\
\hline 1993 & 68.54 & 3.88 & 4.80 & 5.68 & 6.59 & 7.59 & 8.70 & 10.09 & 11.97 & 15.13 & 25.57 \\
1996 & 86.62 & 3.57 & 4.39 & 5.20 & 6.05 & 6.99 & 8.08 & 9.44 & 11.34 & 14.63 & 30.31 \\
1999 & 66.17 & 4.01 & 4.95 & 5.83 & 6.69 & 7.62 & 8.63 & 9.87 & 11.55 & 14.40 & 26.45 \\
2002 & 81.84 & 3.64 & 4.77 & 5.57 & 6.35 & 7.20 & 8.20 & 9.53 & 11.45 & 14.78 & 28.51 \\
\hline
\end{tabular}

Source: World Bank Global Poverty Monitoring Database.

Each row of table 4.1 shows the mean of monthly household expenditures in 1993 Purchasing Power Parity ${ }^{17}$ (PPP) dollars, along with expenditure share of each decile. The year 1993 (our base year) is also the year when Indonesia became a middle-income country according to the World Bank's classification.

Indonesia has a long reputation of high achievements in growth and poverty reduction, even in the face of adverse conditions. In the $1980 \mathrm{~s}$, for instance, the country suffered a serious deterioration in its terms of trade with the rest of the world. The government responded with an aggressive adjustment program. The rate of economic growth slowed down during the adjustment period, but remained positive and above the rate of growth of the population. ${ }^{18}$ Poverty continued to decline over the period.

It is commonly believed that the poverty reduction experienced by the country between 1993 and 1996 (see table 4.2) is part of the trend that started in the mid 1980s. Based on an absolute poverty line of about 2 dollars a day, poverty incidence fell from 61.5 percent in 1993 to 50.5 percent in 1996. Over that period of time, the country also successfully adjusted to the oil price shock, the overheating of the economy early in the

\footnotetext{
${ }^{17}$ The World Bank 1993 PPP conversion factor is equal to 635.655 rupiahs to a dollar. This is what one would use to convert between dollars and local currency in 1993. The local Consumer Price Index (CPI) can then be used to translate these values into values for a year other than 1993.

${ }_{18}$ Population growth per se does not affect our analytical structure: note that the population size $N$, which was introduced in equation (2.1), disappears from all ensuing analysis (see also footnote 1).
} 
1990s, and the increased domestic interest rates to protect the rupiah against the contagion effect of the 1995 Mexican crisis (see World Bank 1995, 1996).

Table 4.2. A Profile of Poverty and Inequality in the 1990s

\begin{tabular}{lcccc}
\hline & 1993 & 1996 & 1999 & 2002 \\
Headcount & 61.53 & 50.49 & 55.29 & 52.41 \\
Poverty Gap & 21.03 & 15.33 & 16.56 & 15.68 \\
Squared Poverty Gap & 9.16 & 6.02 & 6.49 & 6.09 \\
Watts & 28.12 & 19.73 & 21.33 & 20.12 \\
Gini & 32 & 36 & 31 & 34 \\
\hline
\end{tabular}

Source: Authors' calculations.

This track record was briefly reversed by the 1997 Asian financial crisis that took the form of rapid currency depreciation. As a result, real GDP declined by 13 percent in 1998, and real per capita expenditure declined almost 9 percent per year between 1996 and 1999 (based on the data presented in table 4.1), while the incidence of poverty increased from 50.49 percent to about 55 percent in 1999. Since 1999, the country has made some progress in restoring macroeconomic stability and in reducing the economy's vulnerability external shocks. Real per capita expenditure grew on average 7 percent per year between 1999 and 2002, and poverty incidence started heading back to the pre-crisis level, reaching about 52 percent in 2002.

Focusing on the 1993-2002 period, we address the following question: is the observed poverty reduction more or less than what the country would have experienced, had economic growth been distributionally neutral? To answer this question, we consider the following sub-periods: 1993-1996, 1996-1999, and 1999-2002. We also consider a counterfactual for the crisis period 1996-1999. In this case we estimate what might have happened to poverty had per capita expenditure grown by about 9 percent a year instead of declining by the amount implied by the data as presented in table 4.1. We use this aggregate data to recover the underlying size distributions of expenditure from the means and parameterized Lorenz curves. Our parameterization is based on the General Quadratic model described in Datt (1998). We then use numerical integration to compute and interpret measures of pro-poorness according to the analytical framework discussed above for all sub-periods, except 1999-2002. The measures reported for this 
last sub-period are computed on the basis of more detailed information from two household surveys, known as SUSENAS $(1999,2002)$ produced by Statistics Indonesia $(B P S)^{19}$. This information helps us demonstrate the decomposability of our measure of pro-poorness. To ensure consistency with available aggregate data, we convert the household survey data from rupiah into 1993 PPP dollars.

Figure 4.1 shows three growth patterns for Indonesia for the 1996-1999 period the observed pattern, the benchmark and a counterfactual pattern (see on for details of this). The curve representing the actual growth pattern lies entirely below the benchmark for all percentiles way past the headcount ratio (50.49 percent). In fact, the growth patterns for all other sub-periods (not shown here) have this type of configuration too. Thus, theorem 5 leads us to believe that economic growth in Indonesia in the 1990s has not been pro-poor in the sense defined in this paper. In other terms, the process of economic growth has not delivered a significant reduction in poverty, where the level of significance is set at the amount of poverty reduction that would have been achieved under distributional neutrality.

To further illustrate this point empirically, we computed our measure of propoorness according to the formulae for the Watts index, normalized poverty deficit and squared poverty gap given in footnote 7 . The estimates, presented in table 4.3, are calculated using the growth patterns already described.

${ }^{19}$ SUSENAS stands for Survei Sosial Ekonomi Nasional (National Socio-Economic Household Survey), and BPS stands for Badan Pusat Statistik (Central Bureau of Statistics). 
Figure 4.1. Growth patterns (normalized Growth Incidence Curves), 1996-1999

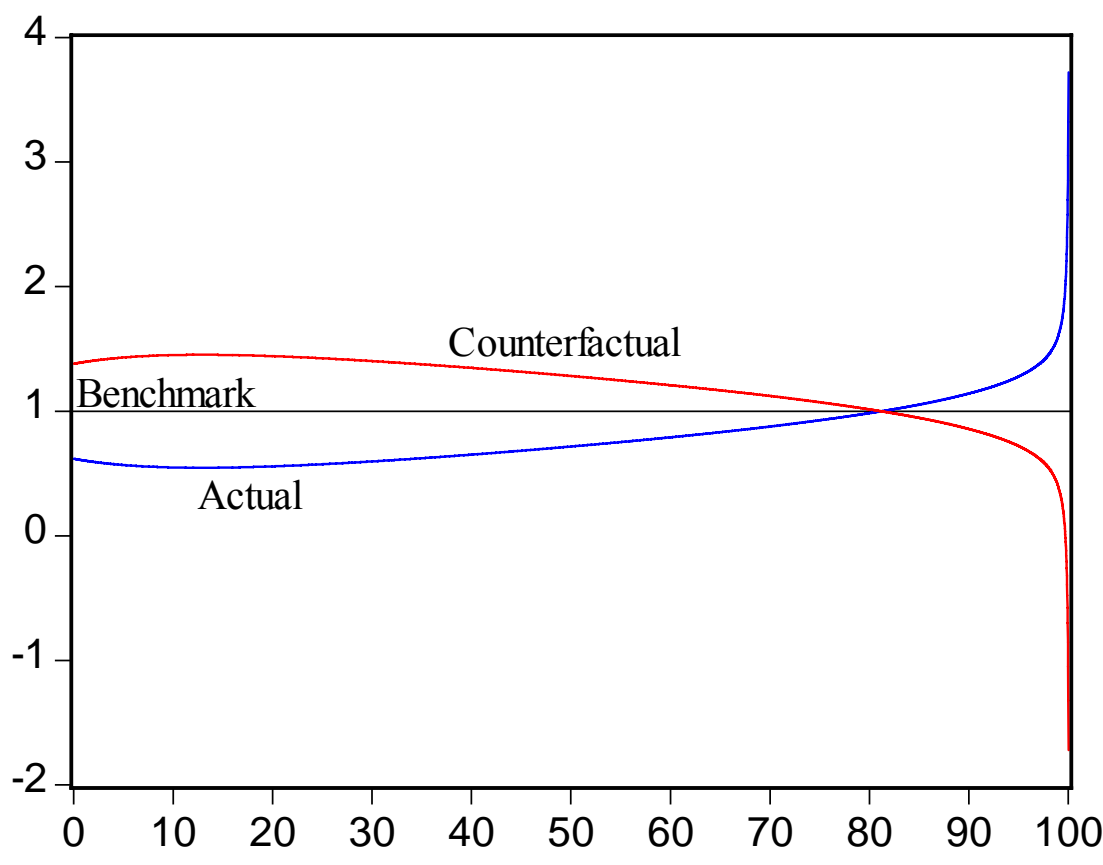

Cumulative Percentage of the Population

It is clear from the results presented in table 4.3 that in the 1990 s economic growth has not been significantly pro-poor in Indonesia. This conclusion holds for all sub-periods and all poverty measures. This could be expected from theorem 5, since the observed growth pattern curves for these periods lie below the benchmark. Interestingly, the results also show that the counterfactual for 1996-1999 would have been pro-poor in the sense of our measure.

Table 4.3. Indicators of Pro-Poorness for the 1990s

\begin{tabular}{lccc}
\hline & Watts & Poverty Gap & Squared Poverty Gap \\
$1993-1996$ & -0.22 & -0.14 & -0.09 \\
$1996-1999$ & -0.20 & -0.14 & -0.08 \\
$1999-2002$ & -0.039 & -0.022 & -0.015 \\
$1993-2002$ & -0.13 & -0.09 & -0.05 \\
$1996-1999$ (Counterfactual) & 0.20 & 0.14 & 0.08 \\
\hline
\end{tabular}

Source: Authors' calculations. 
Another empirical illustration of our theoretical results involves the computation, based on equation (3.11), of the correction factors associated with the PEGR. The results are presented in table 4.4. The adjustment factor is less than one for all observed growth curves, confirming that growth was not pro-poor in Indonesia in the 1990s. The counterfactual for 1996-1999 would have been pro-poor since the correction factor for this pattern is greater than one for all poverty measures considered.

Table 4.4. Estimates of the Correction Factor for the PEGR

\begin{tabular}{lccc}
\hline & Watts & Poverty Gap & Squared Poverty Gap \\
$1993-1996$ & 0.64 & 0.65 & 0.64 \\
$1996-1999$ & 0.60 & 0.61 & 0.58 \\
$1999-2002$ & 0.74 & 0.74 & 0.73 \\
$1993-2002$ & 0.79 & 0.77 & 0.80 \\
$1996-1999$ (Counterfactual) & 1.40 & 1.39 & 1.42 \\
\hline
\end{tabular}

Source: Authors' calculations.

The interpretation of the results presented in tables 4.3 and 4.4 follows the same logic as for the numerical example discussed earlier (see pages 11-12). For the period 1993-1996, the pro-poorness value associated with the Watts index is equal to -0.22 . The underlying elasticities are $\phi_{w}\left(q_{0}\right)=-0.62$ and $\phi_{w}(q)=-0.40$. In other words, for every $1 \%$ increase in per capita expenditure, a distributionally-neutral process would have reduced poverty by $0.22 \%$ more than the observed pattern. In terms of Kakwani et al's adjustment factor, we may say that distributionally neutral growth would have reduced poverty 1.55 times faster than the observed outcome. This is exactly the opposite of the first case discussed in the numerical example. The rest of the results are interpreted similarly.

The basic idea underlying these measures of pro-poorness is, in line with Osmani's (2005) conceptual framework, to compare observed poverty outcomes to what they would have been under distributional neutrality. If observed outcomes are better than the hypothetical ones, economic growth is considered pro-poor, otherwise it is not. We can confirm our basic conclusion by considering the results of a Shapley 
decomposition of poverty outcomes into their growth and distributional components ${ }^{20}$. The magnitude of growth and the induced distribution of gains are partners in the production of the observed changes in overall poverty.

Table 4.5. Shapley Decomposition of Poverty Outcomes

Based on the Poverty Gap Index

\begin{tabular}{cccc}
\hline & Overall & Growth & Distribution \\
$1993-1996$ & -5.70 & -8.83 & 3.13 \\
$1996-1999$ & 1.23 & 4.97 & -3.74 \\
$1999-2002$ & -0.88 & -2.97 & 2.09 \\
$1993-2002$ & -5.35 & -6.87 & 1.52 \\
\hline
\end{tabular}

Source: Authors' calculations

Table 4.5 presents a Shapley decomposition of poverty outcomes (based on the normalized poverty deficit) for the whole and sub-periods covering 1993-2002. The first column represents the observed change in poverty, while the second contains hypothetical changes under distributional neutrality. It is clear that, for all the periods considered, both cases have the same sign and the hypothetical dominates the actual in magnitude. This confirms that poverty reduction has not been significant for the cases considered. The 1996-1999 period is a special case that deserves clarification. Unlike the other periods where the outcome could be explained by the increase in inequality, for this period the distributional effect did alleviate some of the negative impact of the 1997 economic crisis.

\footnotetext{
${ }^{20}$ The Shapley decomposition is based on a microeconomic approach to distributive justice where the key issue is a fair assessment of the productive contributions of partners in a joint venture. The Shapley value of a participant is in general a solution to a cooperative game. If players join the game sequentially, the value of a player is her net addition to overall payoff when she joins. The Shapley value is the average contribution to the payoff over all possible orderings of the participants. For more on the use of the Shapley value in inequality and poverty analysis, see Shorrocks (1999). Our decomposition of poverty elasticity across components is analogous to the Shapley decomposition.
} 


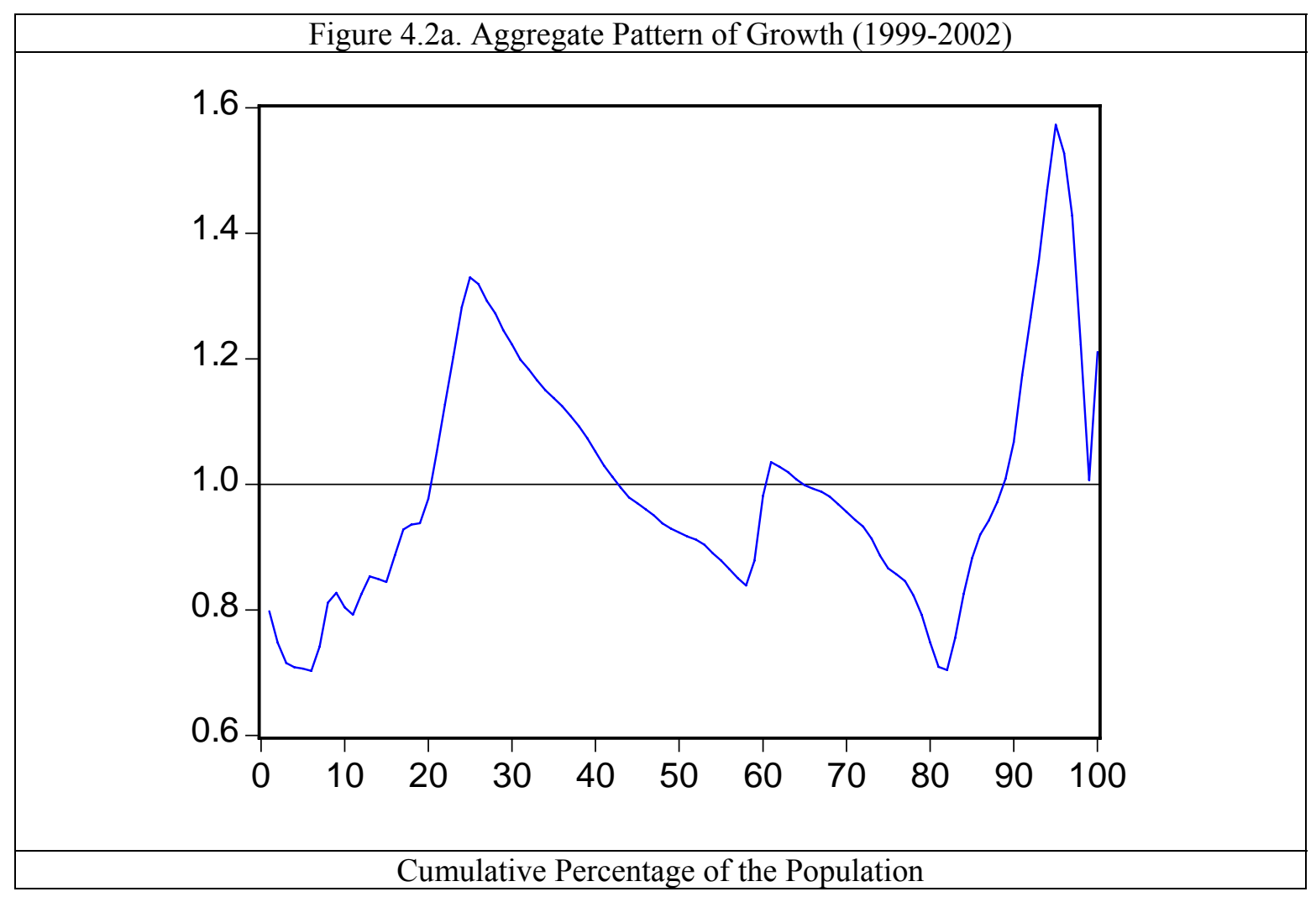

Table 4.6. A Decomposition of Aggregate Measure of Pro-poorness (1999-2002)

\begin{tabular}{lrrr}
\hline & Watts & Poverty Gap & Squared Poverty Gap \\
Rice & -0.173 & -0.125 & -0.062 \\
Other Food & 0.044 & 0.037 & 0.015 \\
Education & 0.005 & 0.003 & 0.002 \\
Health & 0.009 & 0.006 & 0.003 \\
Other Non-Food & 0.077 & 0.057 & 0.027 \\
\hline Aggregate & -0.039 & -0.022 & -0.014 \\
\hline
\end{tabular}

Finally, the available household survey data for 1999 and 2002 allow us to look beyond aggregate results for this period and consider the contribution of expenditure components to the observed outcome. We also use the same data to look at pro-poorness at percentiles. Figure $4.2 \mathrm{a}$ shows the aggregate pattern of growth for the period under consideration while figure $4.2 \mathrm{~b}$ represents a disaggregation of this overall pattern and is 
interpreted as the incidence of economic growth on five expenditure components: (1) rice, (2) other food, (3) education, (4) health, and (5) other non-food ${ }^{21}$.

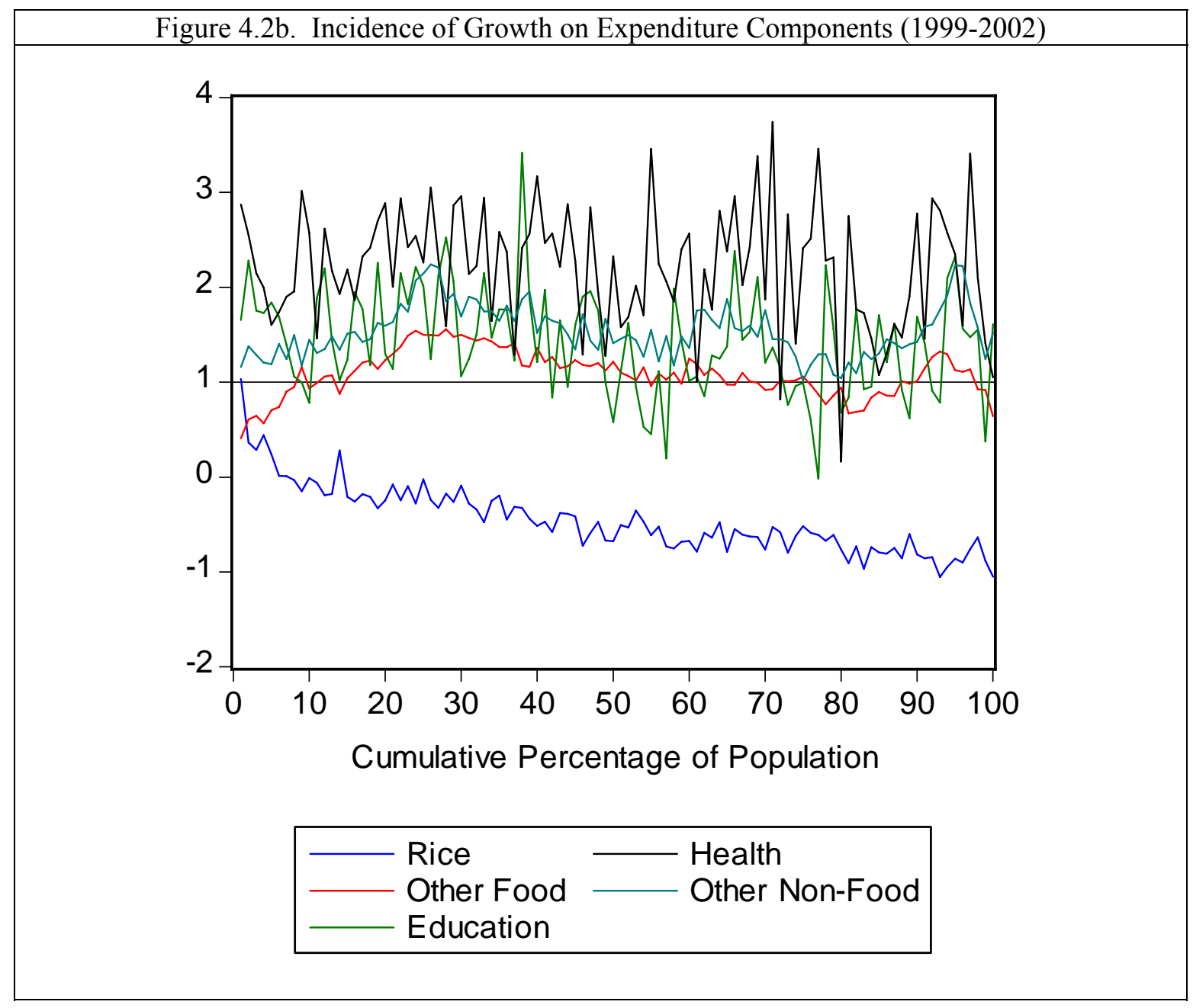

An interesting feature of the aggregate growth curve (figure 4.2a) is that it crosses the benchmark case twice before the head count ratio (55 percent). This means that we cannot use theorem 5 to infer overall pro-poorness. However, the curve lies completely below the benchmark up to the $20^{\text {th }}$ percentile and between the $43^{\text {rd }}$ and $55^{\text {th }}$ percentiles. This represents about 60 percent of the poor for whom expenditure per capita grew less than average. The underlying data show that for this segment of the poor population, on

\footnotetext{
${ }^{21}$ The growth pattern curves presented in figure $4.2(\mathrm{a} \& \mathrm{~b})$ are more refined than those presented in figure 4.1 for instance. This is because they are computed directly from household survey data, whilst the curves in figure 4.1 come from a parameterization of the Lorenz curve based on aggregate data (a distribution of per capita expenditure per decile).
} 
average, per capita expenditure grew 14 percent less than it would have, had growth been distributionally neutral. The other 40 percent of the poor enjoyed an average increase in expenditure 17 percent above the hypothetical case. Figure 4.3 shows plots of propoorness at percentiles $\left[\pi_{J}(q \mid p)\right]$ computed according to theorem 4 for three poverty measures. The fact that all these curves lie below zero indicates that economic growth has not been pro-poor at any percentile up to the headcount. Thus, according to our metric, the benefits enjoyed by the poor located between the $20^{\text {th }}$ and the $43^{\text {rd }}$ percentiles are not high enough to compensate for the loss experienced by those who came before.

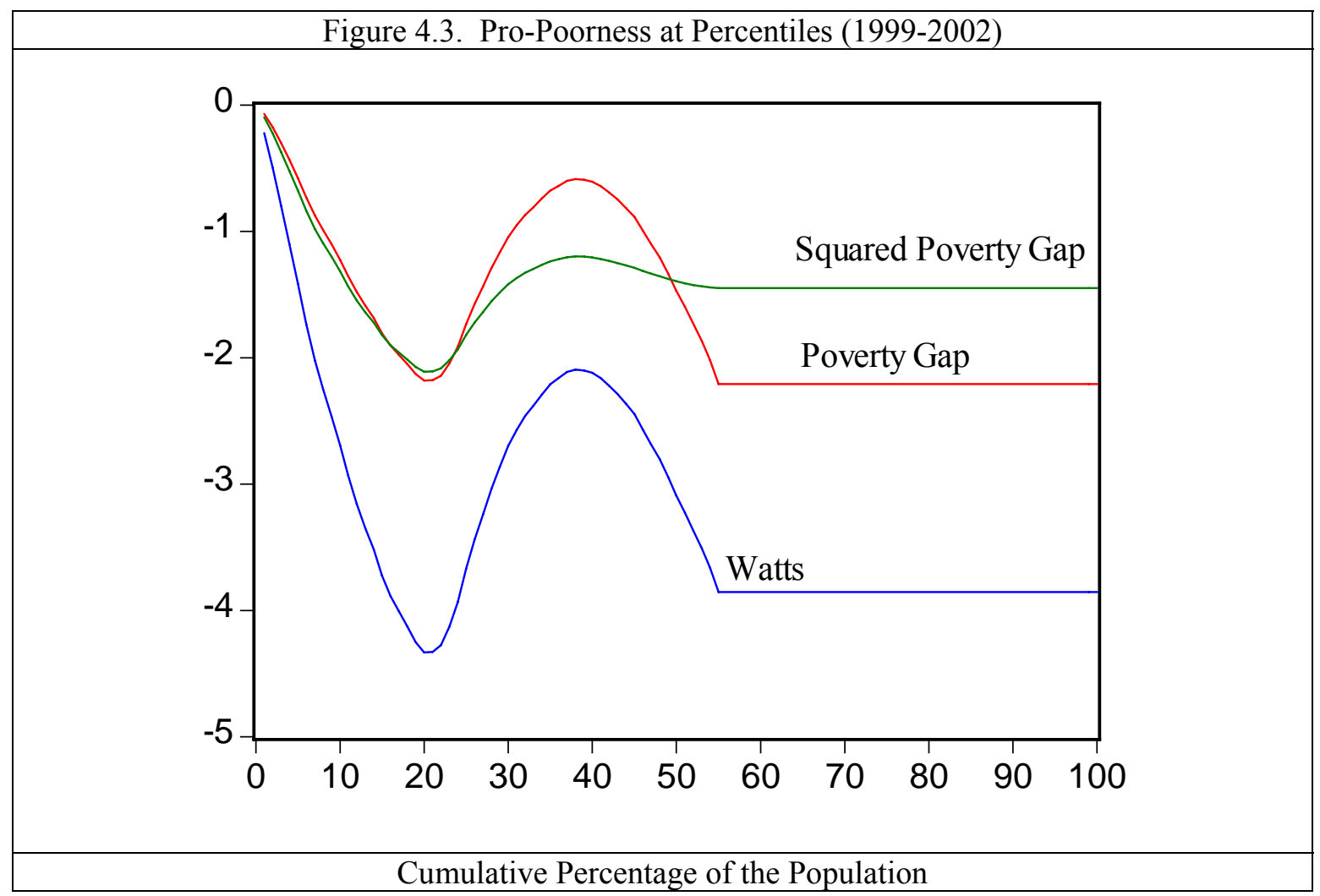

Information on the contributions of expenditure components to pro-poorness is contained in table 4.6. This tells us that the outcome in figure 4.3 is driven mainly by what happened to expenditure on rice, with some help from expenditure on other food items. The underlying data reveals that rice represents 26 percent of total expenditure for the poor (total food expenditure including rice is about 73 percent of household expenditures for the poor). The growth pattern for rice in fact lies entirely below the benchmark, while that for the other food items lies below only for the 20 percent poorest. 


\section{Concluding Remarks}

Poverty reduction is now considered a fundamental objective of development, and therefore has become a metric for assessing the effectiveness of development interventions. Given the fundamental role economic growth plays in reducing income poverty, there has been an increased interest in measurement frameworks to assess the pro-poorness of a growth process. This is an exercise in social evaluation, the outcome of which hinges on the underlying value judgments.

This paper revisits elasticity-based methods and offers a calculus of pro-poorness based on three key elements: (1) the definition of a growth pattern in terms of the point elasticity of individual incomes with respect to total income; (2) the use of individual poverty contributions and members of the class of additively separable poverty measures in the construction of a social evaluation criterion; and (3) the selection of the amount of poverty reduction obtainable under distributional neutrality as the threshold that must be crossed in order to declare a growth pattern pro-poor.

What emerges from this framework is a new measure of the pro-poorness of a growth pattern which can be expressed as a weighted average of the deviations of that growth pattern from the benchmark case. A growth pattern is pro-poor if this average deviation is positive. This measure can be used to assess pro-poorness both in terms of aggregate poverty and at percentiles - unlike the poverty equivalent growth rate (PEGR) measure and associated correction factor of Kakwani et al (2004) - and for income or expenditure components separately. The Kakwani et al measures are also elasticityrelated, as our analysis has shown, but they are not explicitly constructed from the same fundament - namely, from the function $q(x)$ which fully defines an income growth pattern. Nevertheless, each methodology is consistent with the conceptual framework set out by Osmani (2005), and both rest upon the same additively separable class of deprivation-based poverty indices.

An application of this methodology to data for Indonesia for the period of 19932002 shows that the amount of poverty reduction achieved over that period remains far below what distributionally neutral growth would have produced. This conclusion is robust to the choice of both a poverty measure among members of the additively separable class, and a poverty line up to about 2 dollars a day. Also, the behavior of five 
categories of expenditure over the 1999-2002 period suggests that the weak performance observed during that period is due mainly to changes in food expenditure.

\section{Appendix: mathematical results}

Let $U=\int_{0}^{m_{x}} u(x) f(x) d x$ be the average of an attribute $\mathrm{u}(\mathrm{x})$ across the population. Now let total income $y$ grow by a small amount $\Delta y$, so that individual income $x$ grows to $x\left[1+q(x) \cdot \frac{\Delta y}{y}\right]=x+\Delta x$, say. The income value $x+\Delta x$ now occurs with frequency density $\mathrm{f}(\mathrm{x})$, and $U$ changes to $U+\Delta U=\int_{0}^{m_{x}} u(x+\Delta x) f(x) d x$. Writing $u(x+\Delta x)$ $=u(x)+u^{\prime}(x) \Delta x=u(x)+x u^{\prime}(x) q(x) \cdot \frac{\Delta y}{y}$, we have $\Delta U=\frac{\Delta y}{y} \cdot \int_{0}^{m_{x}} x q(x) u^{\prime}(x) f(x) d x$, or:

$$
\frac{y}{U} \cdot \frac{\Delta U}{\Delta y}=\frac{\int_{0}^{m_{x}} x q(x) u^{\prime}(x) f(x) d x}{\int_{0}^{m_{x}} u(x) f(x) d x}
$$

Putting $u(x)=x$ and $U=y$ in (A), $1=\frac{\int_{0}^{m_{x}} x q(x) f(x) d x}{\int_{0}^{m_{x}} x f(x) d x}$ which reduces to equation (2.3). For Theorem 1, just put $u(x)=\psi(x \mid z)$ in (A). Theorem 2 follows directly from Theorem 1 using equation (3.3). For Theorem 4, let $p=F(t) \in[0,1]$ and define $U(t)=$ $\int_{0}^{t} u(x) f(x) d x$. Arguing as before, when total income $\mathbf{y}$ grows by the small amount $\Delta \mathrm{y}$, the change in $U(t)$ is $\Delta U(t)=\frac{\Delta y}{y} \cdot \int_{0}^{t} x q(x) u^{\prime}(x) f(x) d x$, so that:

$$
\frac{y}{U(t)} \cdot \frac{\Delta U(t)}{\Delta y}=\frac{\int_{0}^{t} x q(x) u^{\prime}(x) f(x) d x}{\int_{0}^{t} u(x) f(x) d x}
$$

Now put $u(x)=\psi(x \mid z)$ and $U(t)=J_{P}(p)$ in (B). The growth elasticity of $J_{P}(p)$ is $\zeta_{\mathrm{P}}(\mathrm{q} \mid \mathrm{p})$ $=\frac{\int_{0}^{t} x q(x) \psi^{\prime}(x \mid z) f(x) d x}{J_{P}(p)}$, from which Theorem 4 follows using footnote 10. For Theorem 5, if $\pi_{J}(q \mid p)>0 \forall p \leq p_{0}$ then, as a function of $t \in[0,1]$, 
$\int_{0}^{t}\left\{-x \psi^{\prime}(x \mid z)\right\}[q(x)-1] f(x) d x \quad$ is $\quad$ initially upward-sloping. Taking the derivative, $\exists v<z: q(x)>1 \forall x \in[0, v]$. Conversely, if $\exists v<z: q(x)>1 \forall x \in[0, v]$, then $\int_{0}^{t}\left\{-x \psi^{\prime}(x \mid z)\right\}[q(x)-1] f(x) d x$ is initially upward-sloping, whence $\exists p_{0}<1: \pi_{\mathrm{J}}(\mathrm{q} \mid \mathrm{p})$ $>0 \forall p \leq p_{0}$. Theorem 5 follows. From (3.12) and (2.3), $\pi_{D}(q)=\frac{-1}{z} \int_{z}^{m_{x}} x[q(x)-1] f(x) d x$. Setting $q(x)=q^{*}[x>z$ in this, and using $\int_{z}^{m_{x}} x f(x) d x=\mu \theta$, we have $\frac{1-q^{*}}{z} \cdot \mu \theta=\pi_{D}(q)$, from which Theorem 6 follows.

\section{References}

Atkinson, A.B. (1987). On the measurement of poverty. Econometrica, vol. 55, pp. 749-764.

Chenery, H., M. S. Ahluwalia, C. L. G. Bell, J. H. Duloy and R. Jolly (1974). Redistribution with Growth: Policies to Improve Income Distribution in Developing Countries in the Context of Economic Growth. New York \& Oxford: Oxford University Press.

Datt, Gaurav (1998). Computational tools for poverty measurement and analysis. Washington D.C.: International Food Policy Research Institute (IFPRI) Discussion Paper No. 50 (Food Consumption and Nutrition Division).

Essama-Nssah, B. (2005). A unified framework for pro-poor growth analysis. Economics Letters, vol. 89, pp. 216-221.

Foster, J.E. and A.F. Shorrocks (1991). Subgroup consistent poverty indices. Econometrica, vol. 59, pp. 687-709.

Foster J., J. Greer and E. Thorbecke (1984). A class of decomposable poverty measures. Econometrica, vol. 52, pp. 761-766.

Holland, Paul W. (1986). Statistics and causal inference. Journal of the American Statistical Association, Vol. 81, No. 396: 945-960.

Jenkins, S.P. and P.J. Lambert (1997). "Three 'I's of poverty" curves, with an analysis of U.K. poverty trends. Oxford Economic Papers, vol. 49, pp. 317-327.

Kakwani N. C. (1999). Inequality, welfare and poverty: three interrelated phenomena. In Silber, J. (ed.) "Handbook of Income Inequality Measurement". Boston: Kluwer Academic Publishers. 
Kakwani, N. C. (2004). Methods in measuring poverty matter: an Indian story. One Pager Number 2, International Poverty Center, Brasil.

Kakwani, N.C., S. Khandker and H.H. Son (2004). Pro-poor growth: concepts and measurement with country case studies. Working Paper Number 2004-1, International Poverty Center, Brasil.

Kakwani, N.C. and E.M. Pernia (2000). What is pro-poor growth? Asian Development Review, vol. 18, pp. 1-16.

Kraay, Art. (2004). When is growth pro-poor? Cross-country evidence. Policy Research Paper No. 3225. Washington D.C.: The World Bank.

Lambert, P.J. (1984). Non-equiproportionate income growth, inequality and the income tax. Public Finance/Finances Publiques, vol. 39, pp. 104-118

Osmani, S. (2005). Defining pro-poor growth. One Pager Number 9, International Poverty Center, Brasil.

Ravallion, M. (2004). Defining pro-poor growth: a response to Kakwani. One Pager Number 4, International Poverty Center, Brasil.

Ravallion, M. and S. Chen (2003). Measuring pro-poor growth. Economics Letters, vol. 78, pp. 93-99.

Shorrocks, A. F. (1998). Deprivation profiles and deprivation indices. Pages 250-267 in Jenkins, S., Kaptein, S. A. and van Praag, B. (eds) The Distribution of Welfare and Household Production: International Perspectives. London: Cambridge University Press.

Shorrocks, A.F. (1999). Decomposition procedures for distributional analysis: a unified framework based on the Shapley value. Mimeo, University of Essex.

Son, H.H. (2004). A note on pro-poor growth. Economics Letters, vol. 82, pp. 307-314.

Son, H.H. (2006). Assessing the pro-poorness of government fiscal policy in Thailand. Working Paper No. 15, United Nations Development Program.

Watts, H. (1968). An economic definition of poverty. In D.P. Moynihan (ed.) On Understanding Poverty: Perspectives from the Social Sciences. New York: Basic Books 
World Bank (1995). Indonesia: Improving efficiency and equity-- changes in the public sector's role. Report No.14006-IND. Country Department III, East Asia and Pacific Region. Washington, D.C.: The World Bank.

World Bank (1996). Indonesia: dimensions of growth. Report No.15383-IND. Country Department III, East Asia and Pacific Region. Washington, D.C.: The World Bank.

World Bank (2001). World Development Report 2000/2001: Attacking Poverty. Washington, D.C.: The World Bank and Oxford University Press.

Zepeda, E. (2004) . Pro-poor growth: what is it? One Pager Number 1, International Poverty Center, Brasil. 